\title{
GidADE INTELIGENTE E GOVERNAMENTALIDADE ALGORÍTMICA: LIBERDADE E CONTROLE NA ERA DA INFORMAÇÃO ${ }^{1}$
}

\author{
Marco Antônio Sousa Alves (UFMG)² \\ marcofilosofia@yahoo.com.br
}

Resumo: Partindo das reflexões de Michel Foucault no final dos anos 1970 e da noção desenvolvida mais recentemente de "governamentalidade algorítmica", entendida como um novo regime de poder e saber baseado na coleta, mineração e cruzamento de grandes volumes de dados, o presente artigo pretende analisar criticamente as chamadas "cidades inteligentes" (smart cities), nas quais a infraestrutura e os serviços são interligados de maneira supostamente mais racionalizada e eficiente, oferendo finalmente o sonhado bemestar e a vida feliz. Essa utopia de organização social será associada a uma nova forma de racionalidade política e estratégia de governo por meio de algoritmos, que colocam importantes e inquietantes questões. Neste trabalho, ressaltaremos a capacidade que os algoritmos possuem de nos governar, no sentido de conduzir nossas condutas e estruturar o campo das ações possíveis. E o foco deste artigo recairá sobre a tensão entre liberdade e controle inscrita nessa nova governamentalidade, que tem por objeto mais imediato os dados, as relações e os ambientes.

Palavras-chave: Smart City. Governamentalidade algorítmica. Foucault. Liberdade.

\section{INTRODUÇÃO.}

Não é de hoje que o ser humano sonha com uma vida segura, organizada de maneira eficiente, em um ambiente

\footnotetext{
${ }^{1}$ Recebido: 30-04-2018/ Aceito: 07-12-2018/ Publicado online: 01-02-2019.

2 Doutor em filosofia e professor Adjunto de Teoria e Filosofia do Direito na Universidade Federal de Minas, UFMG, Minas Gerais, Brasil.
} 
confortável, moldado para atender às suas necessidades e desejos. Esse sonho humano passa geralmente por uma reflexão sobre a organização urbana e por uma série de construções utópicas de cidades. Não é diferente nos dias atuais. A emergência de novas tecnologias está intimamente associada a novos projetos urbanos e a uma nova utopia de cidade. Este artigo tem por objetivo voltar-se para o impacto das tecnologias da comunicação e da informação em nossa experiência urbana, o que vem dando forma às chamadas "cidades inteligentes" (smart cities), nas quais a infraestrutura e os serviços são interligados de maneira supostamente mais racionalizada e eficiente, oferendo finalmente o sonhado bem-estar e a vida feliz.

O objetivo deste trabalho, contudo, não reside em uma contribuição para a reflexão urbanística. Ao menos não diretamente. Tal propósito, inclusive, estaria distante da formação e das capacidades do autor deste artigo. Também não se trata de uma mera descrição desse novo fenômeno ou de uma defesa desse tipo de iniciativa. As utopias urbanas e o sonho da smart city servirão, sobretudo, para ilustrar uma nova estratégia de governo característica da contemporaneidade. Em suma, o objetivo deste trabalho possui uma natureza mais propriamente filosófica, voltada para a compreensão de uma nova racionalidade política e um novo sonho de organização social, que colocam importantes e inquietantes questões acerca do exercício da liberdade humana nesses novos ambientes.

Este artigo pretende abordar esse fenômeno da smart city a partir da noção de "governamentalidade algorítmica" (gouvernementalité algorithmique), entendida como um novo regime de poder e saber baseado na coleta, mineração e cruzamento de grandes volumes de dados. Tal noção vem 
sendo desenvolvida recentemente a partir de algumas reflexões feitas por Michel Foucault, em especial a partir do curso ministrado em 1978 no Collège de France, publicado com o título Segurança, Território, População, ressaltandose a capacidade que os algoritmos possuem de nos governar, no sentido de conduzir nossas condutas e estruturar o campo das ações possíveis. $\mathrm{O}$ foco deste artigo recairá sobre a tensão entre liberdade e controle inscrita nessa nova governamentalidade, que tem por objeto mais imediato os dados, as relações e os ambientes.

$\mathrm{O}$ artigo está estruturado em cinco partes. Na primeira, realizar-se-á uma apresentação de como a noção de governo foi concebida no seio da analítica do poder desenvolvida por Michel Foucault a partir do final dos anos 1970, destacando o neologismo "governamentalidade" cunhado naquele momento em associação com a descrição do funcionamento dos dispositivos de segurança. Na segunda parte, será analisada a noção de governamentalidade algorítmica, que tem por ponto de partida as reflexões foucaultianas, estendendo-as para se pensar fenômenos próprios da contemporaneidade. Na terceira parte do artigo, o foco será dirigido para o sonho da smart city, analisando-se o surgimento dessa utopia e alguns de seus traços mais característicos. Na quarta parte, será realizada uma reflexão crítica desse sonho, ressaltando os riscos trazidos pelo esforço de personalização da vida urbana no que diz respeito à perda da experiência comum. Por fim, na quinta e última parte, algumas considerações críticas serão apresentadas no sentido de questionar o possível comprometimento da própria liberdade humana no seio dessa cidade governada por algoritmos. 


\section{PODER E GOVERNO EM MiCHEL FOUGAULT}

A noção de governamentalidade algorítmica, concebida para pensar fenômenos emergentes na contemporaneidade, especialmente a partir do século XXI, é um claro desenvolvimento a partir das reflexões realizadas por Michel Foucault sobre a noção de governo no seio de seu projeto de uma analítica do poder, o que ocupou boa parte de sua produção intelectual do final dos anos 1970 e do início dos anos 1980. Nesse período, Foucault passou a analisar as relações de poder nos termos de práticas de governo, sobre si mesmo ou sobre os outros, no campo da ética ou da política.

Em suma, governar para Foucault envolve dirigir ou mover alguém de forma calculada, o que implica regular a conduta dos outros ou de si mesmo de uma maneira mais ou menos racional e sistemática, visando fins específicos. Tratase de uma atividade que afeta, guia e formata a ação de si mesmo ou dos outros, em especial de uma população. Mais do que fazer uso da mera violência, no sentido de agir diretamente sobre um corpo, forçando-o e submetendo-o à força, as relações de poder que Foucault descreve por meio das práticas de governo têm por objeto imediato a ação, pressupondo, por meio de um complexo jogo agônico, uma determinada liberdade de agir. Foucault (1995, p. 243) deixa esse ponto claro no texto que veio a público em 1982 sob o título de $O$ sujeito e o poder: "aquilo que define uma relação de poder é um modo de ação que não age direta e imediatamente sobre os outros, mas age sobre sua própria ação. Uma ação sobre a ação, sobre ações eventuais, ou atuais, futuras ou presentes".

Na sequência desse mesmo texto, Foucault (1995, p. 243) explica o modo como se dá o exercício do poder nos 
seguintes termos:

É um conjunto de ações sobre ações possíveis; ele [o poder] opera sobre o campo de possibilidade onde se inscreve o comportamento dos sujeitos ativos; ele incita, induz, desvia, facilita ou torna mais difícil, amplia ou limita, torna mais ou menos provável; no limite, ele coage ou impede absolutamente, mas é sempre uma maneira de agir sobre um ou vários sujeitos ativos, e o quanto eles agem ou são suscetíveis de agir. Uma ação sobre ações.

Procurando desenvolver uma nova descrição daquilo que há de específico nas relações de poder, agora por meio da noção de governo, Foucault afasta-se nesse momento não apenas do “discurso jurídico do poder", centrado na questão da soberania, na forma da lei e na ficção do contrato social, como já havia feito quando iniciou o projeto de uma analítica do poder no início dos anos 1970, mas opera um novo deslocamento, abandonando também a "hipótese de Nietzsche" que utilizou para pensar as relações de poder de maneira binária e belicosa, como vemos especialmente no curso ministrado no Collège de France em 1976, intitulado Em defesa da sociedade. Nesse sentido, cito novamente Foucault (1995, p. 244):

O exercício do poder consiste em "conduzir condutas" e em ordenar a probabilidade. O poder, no fundo, é menos da ordem do afrontamento entre dois adversários, ou do vínculo de um com relação ao outro, do que da ordem do "governo". [....] Governar, neste sentido, é estruturar o eventual campo de ação dos outros. O modo de relação próprio ao poder não deveria, portanto, ser buscado do lado da violência e da luta, nem do lado do contrato e da aliança voluntária (que não podem ser mais do que instrumentos); porém, do lado deste modo de ação singular - nem guerreiro nem jurídico - que é o governo.

Caminhando nessa direção, Foucault voltou-se a partir do final dos anos 1970 para a análise do governo, ou mais 
exatamente das artes de governar. Nos termos propostos por Foucault, o foco do governo reside assim na condução de condutas, ou seja, no direcionamento dos comportamentos por meio de incitação, indução, sedução ou constrangimento e proibição, de modo a tornar mais ou menos provável um determinado curso de ação. Nas aulas de $1^{\circ}$ e 8 de fevereiro de 1978, no seio do curso intitulado Segurança, Território, População, Foucault (2008, p. 117-180) desenvolve uma breve genealogia do governo. Ele começa observando como tal noção possuía no século XVI um sentido em geral bem mais amplo do que aquele associado simplesmente à administração pública ou às instituições políticas, envolvendo também o governo de si mesmo, das crianças, das famílias, dos doentes, da população, etc. Mas, apesar da multiplicidade de sentidos, algo em comum é destacado na ação de governar: são sempre os homens que são governados. Esse ponto é deixado claro por Foucault (2008, p. 164) na aula de 8 de fevereiro de 1978: "nunca se governa um Estado, nunca se governa um território, nunca se governa uma estrutura política. Quem é governado são sempre pessoas, são homens, são indivíduos ou coletividades".

Aprofundando a análise genealógica da arte de governar, Foucault explora o chamado "poder pastoral", enfatizando a especificidade do poder que o pastor exerce sobre seu rebanho, e que constitui uma metáfora muito comum no cristianismo. Trata-se de um poder que se exerce sobre as pessoas em seu movimento, no sentido de conduzi-las, de "cuidar" delas. Ao invés de um poder que se exerce sobre a unidade de um território, o poder pastoral é exercido, nas palavras de Foucault (2008, p. 168), "sobre uma multiplicidade em movimento".

Diferentemente das leis, que constituem o instrumento 
característico da lógica da soberania centrada no domínio sobre um território, Foucault observa que o governo visa não mais impor leis, mas sim dispor as coisas de forma a atingir certos fins específicos. Para governar é preciso conhecer as coisas por meio de um saber eminentemente estatístico e dispô-las de modo a atingir os objetivos propostos. A nova arte de governar, que acompanha o nascimento do Estado moderno e faz parte do processo que Foucault designará de governamentalização do Estado, está ligada aos desenvolvimentos a partir do século XVI do aparelho administrativo e de um conjunto de análises e saberes, em especial a economia política. Nesse sentido, Foucault (2008, p. 219) afirma na aula de 22 de fevereiro de 1978 que “o Estado moderno nasce [...] quando a governamentalidade se torna efetivamente uma prática política calculada e refletida”.

Feitos esses esclarecimentos sobre a noção de governo, que emerge no seio da analítica do poder a partir do final dos anos 1970, resta agora explicar por que Foucault cunha o termo 'governamentalidade', um neologismo que serve para se referir a uma racionalidade refletida, sistematizada e regulada de governo, que vai além de um exercício espontâneo de poder. Governar, nesse sentido, significa regular a conduta racionalmente, por meio de tecnologias apropriadas. A palavra governa/mentalidade (gouverne/mentalité) ressalta essa dupla referência ao governo e à mentalidade ou racionalidade governamental, no sentido de uma prática refletida.

Com esse neologismo, Foucault procura ressaltar um conjunto de procedimentos, cálculos e táticas que permitem o exercício de uma forma específica de poder, que tem por alvo principal a população. Nas três primeiras aulas do curso Segurança, Território, População, ministradas no Collège 
de France nos dias 11, 18 e 25 de janeiro de 1978, Foucault (2008, p. 3-116) aponta para três modos de funcionamento do poder e para três estratégias distintas: os mecanismos de soberania (baseados no sistema jurídico), os mecanismos disciplinares (baseados em estratégias de vigilância e correção dos indivíduos) e os dispositivos de segurança ou de governamentalidade (baseados em cálculos de probabilidade e em levantamentos estatísticos visando regular uma população). Foucault sustenta ainda que teria havido ao longo dos últimos séculos uma tendência de proeminência da estratégia governamental sobre as estratégias características da soberania ou da disciplina. Assim, como dito acima, Foucault defende que o Estado sofreu um processo de governamentalização.

Para ilustrar esses argumentos, valho-me aqui de um exemplo do próprio Foucault (2008, p. 17-28), of erecido na aula de 11 de janeiro de 1978, quando cita três cidades planejadas. Interessante perceber que o próprio Foucault se vale neste momento da questão urbanística ou das diferentes utopias de cidade justamente para ilustrar sua argumentação e clarear as diferenças entre o funcionamento do poder de soberania, os mecanismos disciplinares e os dispositivos de segurança ou de governamentalidade. Primeiro, Foucault cita o projeto utópico de uma cidade chamada La Métropolitée, concebido no século XVII por Alexandre Le Maître. Nesse projeto, que ilustra a estratégia de poder de soberania, tudo é organizado em torno da capital, de um centro político e comercial. O segundo projeto citado por Foucault é o da cidade artificial de Richelieu, construída a partir do nada no século XVII, tendo por inspiração o modelo disciplinar dos acampamentos romanos. Nessa cidade, o espaço é arquite- 
tado, esquadrinhado e organizado segundo princípios de hierarquização e de distribuição funcional, visando assegurar de maneira idealizada o comércio, a moradia, a circulação, etc. Por fim, o terceiro exemplo citado por Foucault é o da urbanização de Nantes no século XVIII, que visou desfazer as aglomerações desordenadas e, baseando-se em dados estatísticos e em estimativas de probabilidades, abriu espaços e alargou eixos e ruas procurando prover a circulação e prever o crescimento urbano.

Nantes, essa terceira cidade analisada por Foucault, ilustra a estratégia dos dispositivos de segurança ou da governamentalidade. Ao invés de fazer tábula rasa, de começar do zero e de projetar uma cidade ideal artificial, como vemos no sonho disciplinar ilustrado pela cidade de Richelieu, a segurança trabalha sobre algo dado, visando maximizar os elementos positivos e minimizar os riscos e inconvenientes. Não de trata mais de buscar a perfeição, mas sim de gerir uma população segundo uma média verificada. Nos dispositivos de segurança, a norma emerge dos dados eles mesmos, e o foco da ação é de natureza preventiva. Trabalha-se com o futuro, levando-se em conta o que pode acontecer e procurando tornar certos comportamentos mais ou menos prováveis.

\section{A GOVERNAMENTALIDADE ALGORÍTMICA}

Um enorme campo de estudos abriu-se a partir dessas reflexões de Foucault sobre a governamentalidade. A partir dos anos 1990 vemos nascer, especialmente nos Estados Unidos, o que se convencionou chamar de governmentality studies. ${ }^{3}$

\footnotetext{
${ }^{3}$ Uma obra importante nesse sentido foi a coletânea publicada em 1991 com o título The Foucault
} 
Um desses desdobramentos está na utilização dessa noção para se pensar a nova dinâmica de regulação e controle de nossas ações por meio de diversos dispositivos tecnológicos de informação e comunicação. ${ }^{4}$

Em primeiro lugar, é preciso deixar claro o que significa "governamentalidade algorítmica", que pode ser aproximada de outras noções que orbitam sobre problemas similares, como "governança por números", "razão digital" ou "política do big data". Trata-se, em suma, de uma estratégia de governo por meio de algoritmos, ou seja, de uma condução de condutas que se vale das novas tecnologias da informação. Assim, antes de avançarmos em nossa análise, é fundamental esclarecer o que são os algoritmos. Em princípio, eles nada mais são do que conjuntos de instruções implementados por meio de uma linguagem particular. Em geral, os algoritmos trabalham nos bastidores, implicitamente, sem que tenhamos muita consciência de suas operações. Nesses termos, ao menos em princípio, os algoritmos não devem ser simplesmente demonizados por meio de uma atitude passadista, que acusa a desumanização do mundo e

effect: studies in governmentality (BURCHELL; GORDON; MILLER, 1991). Outras duas importantes coletâneas que permitem ver a pluralidade dos estudos sobre a governamentalidade e suas múltiplas aplicações vieram a público com o título Foucault and political reason: liberalism, neo-liberalism and rationalities of government (BARRY; OSBORNE; ROSE, 1996) e Governmentality: current issues and future challenges (BRÖCKLING; KRASMANN; LEMKE, 2011). Convém destacar ainda, mais recentemente, o estudo sobre a noção de governamentalidade em Foucault na obra intitulada Foucault, governmentality, and critique (LEMKE, 2012) e o trabalho sobre a racionalidade governamental nas sociedades liberais "avançadas" em Governando o presente: gerenciamento da vida econômica, social e pessoal (MILLER; ROSE, 2012).

${ }^{4}$ Nesse sentido podemos situar os seguintes trabalhos: La politique des grands nombres: histoire de la raison statistique (DESROSIÈRES, 1993), La gouvernance par les nombres (SUPIOT, 2015), Algorithms to live by (CHRISTIAN; GRIFFITHS, 2016), Weapons of math destruction (O'NEIL, 2016), À quoi rêvent les algorithmes: nos vies à l'heure des big data (CARDON, 2015), La vie algorithmique: critique de la raison numérique (SADIN, 2015), Le temps des algorithmes (ABITEBOUL; DOWEK, 2017) e Network culture: politics for the information age (TERRANOVA, 2004). No Brasil, a recepção dessas questões pode ser observada, por exemplo, nos trabalhos de Fernanda Bruno (2013; 2016), Henrique Parra (2016) e Edson Teles (2017; 2018). 
teme qualquer mudança, vivendo da nostalgia de um passado idealizado (ABITEBOUL; DOWEK, 2017, p. 110). Mas, ainda que não devam ser vistos como uma espécie de mal em si mesmo, tomados como o "bode expiatório” de todos os problemas da contemporaneidade, não podemos também negar o fato de que, nas sociedades contemporâneas, os algoritmos são cada vez mais relevantes enquanto tecnologia de governo, suscitando diversas questões novas e inquietantes. Para se dar conta disso, basta pensar em alguns serviços hoje oferecidos pela Google, pelo Facebook, pelo Uber, pelo Waze ou pelo Netflix. Somos cada vez mais influenciados em nossas escolhas e condutas, em suma governados, por esses dispositivos, no sentido de que nossas ações são claramente direcionadas, moldadas ou afetadas por eles.

O fato de os algoritmos funcionarem de maneira invisível e de constituírem uma espécie de “caixa preta” só atesta a máxima foucaultiana de que o poder funciona de maneira tanto mais eficiente quanto mais mascarado e desapercebido ele for. Nesse sentido, cito Foucault (1988, p. 83), em uma passagem retirada do primeiro volume da História da sexualidade: a vontade de saber:

Razão geral e tática que parece se impor por si mesma: é somente mascarando uma parte importante de si mesmo que o poder é tolerável. Seu sucesso está na proporção daquilo que consegue ocultar dentre seus mecanismos. O poder seria aceito se fosse inteiramente cínico? O segredo, para ele, não é da ordem do abuso; é indispensável ao seu funcionamento.

Diversas decisões de instituições públicas ou privadas são hoje assentadas em algoritmos que trabalham com uma enorme massa de dados e realizam correlações e cálculos de grande complexidade. Esses cálculos podem servir de base 
para negar um visto, para identificar um suspeito, para oferecer produtos, para sugerir filmes, para indicar amigos, para conceder crédito, para fixar o valor de uma apólice de seguros, para recrutar profissionais ou para milhares de outras aplicações.

A governamentalidade algorítmica pode ser entendida, em suma, como um novo modo de governo das condutas, ligado à emergência de um novo regime de verdade, movido pela busca de objetividade, eficiência e segurança. Nos últimos dez anos, essa noção vem sendo trabalhada pela filósofa do direito belga Antoinette Rouvroy, que hoje é professora na Université de Namur e pesquisadora no Centro de Pesquisa em Informação, Direito e Sociedade (Centre de $R e^{-}$ cherche en Information, Droit et Société - CRIDS). Ela define a governamentalidade algorítmica em termos claramente foucaultianos, como um tipo de racionalidade governamental que "repousa sobre a coleta, agregação e análise automatizada de dados em quantidade massiva de modo a modelizar, antecipar e afetar, por antecipação, os comportamentos possíveis" (ROUVROY; BERNS, 2015, p. 42). Para entender a especificidade dessa nova estratégia de governo, três operações básicas são ressaltadas: a dataveillance, o data-mining e o profiling.

Em primeiro lugar, temos a vigilância e coleta automatizada de dados (dataveillance), que dá forma ao que chamamos de big data, uma massa que ultrapassa trilhões de gigabytes de informação constituída por todo tipo de rastro digital: tráfego de dados na internet, cliques, compartilhamentos em mídias sociais, rastreamento de GPS, dados móveis, imagens de câmeras de segurança e de satélite, transações bancárias, etc. Além do que fazemos diretamente na internet, diversos dispositivos são hoje responsáveis por 
produzir dados, emitindo informações sobre nossos deslocamentos, nossas atividades diárias, nosso consumo calórico, o estilo de vida que levamos, etc. Esses novos objetos "inteligentes" ou conectados dão forma ao que se convencionou chamar de internet das coisas. Assim, alimentamos os gigantescos bancos de dados (datawarehouses) o tempo inteiro, mesmo quando estamos off-line. Hoje em dia, em suma, quando trabalhamos, consumimos ou viajamos, estamos produzimos dados inevitavelmente. Dados esses que são coletados e permitem diversos usos e aplicações, sem que tenhamos quase nenhuma clareza sobre isso.

Além de coletados em massa by default, esses dados são processados e correlacionados (datamining) tendo em vista a produção de um novo tipo de conhecimento. Tomados isoladamente, esses dados brutos parecem inofensivos, anônimos e impossíveis de serem controlados. Eles só ganham "sentido" quando correlacionados, trabalho este que é realizado de maneira automatizada e em grande escala. Diferentemente da estatística tradicional, esse conhecimento baseia-se nos dados eles mesmos, sem nenhuma categoria pré-concebida ou hipótese formulada previamente. A produção de hipóteses faz-se a partir dos próprios dados.

Por fim, essas correlações dão origem a perfis que permitem antecipar comportamentos individuais ou de grupos e agir sobre as ações futuras. A elaboração algorítmica de perfis (profiling) constitui um tipo de saber prospectivo, que elabora previsões probabilísticas quanto às preferências, intenções e propensões de ação, constituindo uma antecipação de comportamentos. Mais do que os sujeitos tomados diretamente, a nova estratégia focaliza imediatamente apenas as relações elas mesmas, agindo no sentido de conformar ambientes e dirigir o campo das ações possíveis. 
Em suma, estamos claramente diante de uma nova governamentalidade, no sentido proposto por Foucault, ou seja, uma maneira de tornar o mundo previsível e ser capaz de agir eficazmente e de modo calculado sobre a ação dos outros. Quanto maior a massa de dados correlacionados, maior a eficácia preditiva. Trata-se também de trabalhar como o futuro: levar em conta o que pode acontecer (uma gestão de séries abertas, controladas por estimativas de probabilidades). É assim que, por exemplo, funcionam hoje diversos dispositivos voltados para a disponibilização de crédito, para uma tomada de decisão de intervenção cirúrgica, para a tarifação de um contrato de seguro, para sugestão de compras direcionadas, para a elaboração de uma propaganda eleitoral dirigida, etc.

E mais do que uma ação direta sobre os indivíduos, como havia pensado Foucault ao descrever o poder pastoral, a governamentalidade algorítmica se concentra sobre relações. Trata-se mais exatamente, ou pelo menos de maneira mais imediata, de um "governo das relações", que age conformando ambientes (ROUVROY; BERNS, 2015, p. 49). Na medida em que nosso agir é reativo e inteligente, a ação por antecipação sobre nossos comportamentos pode limitarse a uma intervenção sobre o ambiente. Assim, evita-se toda forma de restrição direta sobre a ação individual, o que torna a prática do governo por algoritmos ainda mais insidiosa e eficiente (ROUVROY; BERNS, 2015, p. 41). Não é mais preciso dizer "não" ou ameaçar: basta enviar sinais capazes de provocar ou estimular determinados reflexos ou respostas a certos estímulos. Em suma, estamos diante de uma espécie de comportamentalismo ou behaviorismo de dados. 
Age-se, dessa maneira, em um nível eminentemente infra-individual, sem que se faça qualquer apelo ao entendimento ou à vontade dos indivíduos governados para se passar ao ato. Temos assim um novo regime de ação sobre o futuro. Não se trata mais, como acontecia na prevenção tradicional, de agir sobre as causas de um fenômeno. Ao invés disso, trata-se de agir imediatamente sobre o ambiente, de modo a fazer com que certas coisas sejam atualizadas ou não, tornem-se mais ou menos prováveis. Os indivíduos são assim afetados de maneira mediata, sendo governados na medida em que o campo de suas ações possíveis viu-se afetado. Desse modo, temos um governo mais eficiente e um poder que funciona de modo ainda mais insidioso, pervasivo e cirúrgico. E esse foco direcionado para a conformação dos ambientes favorece ainda mais uma reflexão sobre os projetos de organização urbana, como veremos a seguir.

Desse modo, a governamentalidade algorítmica contorna e evita os sujeitos humanos reflexivos. Ela se alimenta de dados brutos que são insignificantes neles mesmos e, a partir dessa base, cria modelos de comportamento ou perfis supra-individuais sem jamais interpelar o sujeito, sem jamais convocá-lo a dar-se conta por si mesmo daquilo que ele é ou daquilo que poderia tornar-se (ROUVROY; BERNS, 2015, p. 42; ROUVROY; STIEGLER, 2015, p. 122). Procuraremos ressaltar na sequência deste trabalho, ao analisar a utopia das smart cities, como esse fenômeno permite levantar diversas inquietações de natureza ética e política.

\section{A GIDADE GOVERNADA: O SONHO DA SMART CITY}

Como fez Foucault no curso de 1978, ao tratar dos projetos de La Métropolitée, de Richelieu e de Nantes, elaborados ao 
longo dos séculos XVII e XVIII, gostaria de ilustrar essa nova estratégia de governo por meio de algoritmos apelando também para um novo sonho de cidade: a "cidade inteligente" ou smart city. Sem dúvida, as configurações da experiência urbana estão intimamente relacionadas com as estratégias de governo e as racionalidades de poder. A história das modernas cidades europeias, por exemplo, pode ser vista em associação com uma clara ampliação de iniciativas regulatórias, relacionadas a questões sanitárias, políticas de saúde pública, controles da moralidade, regulação da vida privada, combate à vagabundagem, proibição da prostituição e da mendicância, expansão da "civilidade", regulação do mercado de trabalho ou ações de policiamento (HUNT, 1996, p. 177). Temos uma espécie de "impulso regulatório" que é posto em funcionamento por meio de diversas práticas de governo.

Para compreender essa nova utopia de cidade, comecemos por alguns esclarecimentos. Smart city ou "cidade inteligente" é o nome dado ao emprego integrado de tecnologias para trazer mais eficiência no uso dos recursos, mobilidade e serviços de uma cidade, permitindo administrar hospitais, iluminação pública, transportes, tratamento de água, coleta de lixo, segurança pública e outras atividades. O objetivo declarado consistiria em of erecer maior bem-estar por meio de uma experiência mais confortável, eficiente e segura da cidade, com um controle mais inteligente dos fluxos e uma securitização generalizada. $\mathrm{O}$ sonho mobilizado aqui consiste na construção de uma vida social cada vez mais produtiva e harmônica, com o mínimo de perda, de desperdício e de prejuízos.

A noção de smart city é extremamente recente, remontando ao início do século XXI, quando a ideia de uma 
"internet das coisas" (internet of things - IoT) começou a ganhar forma, apontando para uma experiência de digitalização e conexão global capaz de ultrapassar o espaço restrito da tela dos computadores para se estender às coisas em geral e ao espaço urbano. Em suma, a cidade inteligente nasce da possibilidade de grandes volumes de dados serem produzidos incessantemente por seus habitantes, infraestruturas e serviços, por meio de uma arquitetura de rede de conexão sem fio abarcante e fiável, etiquetas digitais geolocalizadas disseminadas nos mais variados objetos, sistemas de filtragem e tratamento do fluxo de dados e uso de realidade aumentada visando oferecer uma experiência contextual enriquecida.

Em posse desse grande volume de dados e das novas ferramentas da tecnologia da informação, a organização urbana passa a ser concebida como um espaço construído de maneira automatizada e em tempo real, ajustando os fluxos e regulando diversas situações: a rede de transportes, os sinais de trânsito, a distribuição de energia, o policiamento, etc. Os novos aplicativos de mobilidade urbana (Uber, Cabify, etc.) ilustram bem esse novo tipo de ferramenta, baseada na coleta em tempo real de dados. Eles são capazes de se ajustar melhor à demanda de circulação pela cidade, permitindo modular o preço das tarifas, antecipar os melhores trajetos e alocar os recursos disponíveis de forma muito mais eficiente e lucrativa do que o antigo serviço de taxi.

Em seu livro A vida algorítmica, Sadin (2015, p. 80) ressalta que a ideia de smart city remete ainda, em grande medida, não a uma realidade plenamente efetivada, mas apenas a um movimento que aos poucos experimenta alguns projetos aqui e ali, dos quais não temos ainda qualquer garantia quanto à viabilidade deles. Mesmo sendo um projeto 
que permanece ainda, em grande medida, no domínio da ficção, Sadin (2015, p. 81) ressalta que as grandes metrópoles do mundo já vêm travando entre si uma intensa competição no sentido de assumir a imagem de cidade global, criativa e conectada, apta a atrair investimentos, empresas e pessoas qualificadas. No domínio da segurança pública, por exemplo, encontramos diversas iniciativas nesse sentido em grandes cidades pelo mundo, como o Centro de Operações que foi implementado no Rio de Janeiro para fins securitários durante os Jogos Olímpicos de 2016 e que permanece em funcionamento, como um "legado" para a cidade.

Além dessas intervenções em grandes cidades já constituídas e portadoras de um longo passado histórico, projetos experimentais mais ousados e abarcantes vêm sendo desenvolvidos, envolvendo a criação ex nihilo de novos espaços urbanos, em geral conduzidos por consórcios privados e voltados para gigantescas zonas residenciais luxuosas, como vemos em Abu Dhabi (Masdar), na Coréia do Sul (Songdo), nos Estados Unidos (Peña Station NEXT e Babcock Ranch) e no Japão (Fujisawa Smart Town). Nesses projetos em andamento, vemos o sonho da smart city alçar voos bem mais altos. Sensores e câmeras monitoram diversas atividades, carros automáticos circulam pelas ruas, drones atendem chamados de emergência e milhares de objetos com etiquetas digitais conectam-se de modo a mandar informações e conformarem um ambiente cada vez mais adaptado, climatizado, eficiente, seguro e confortável. Em suma, as cidades inteligentes constituem a maior utopia urbana contemporânea, a imagem da urbe como um grande e eficiente robô, o velho sonho de uma vida melhor permitida pelo avanço ilimitado da tecnologia. 
Nessa nova experiência urbana, vemos também se articular diversos dispositivos de poder, que podem ser aproximados aos mecanismos disciplinares e biopolíticos. No último capítulo do primeiro volume da História da sexualidade: a vontade de saber, Foucault (1988, p. 131) deixa claro como o poder sobre a vida desenvolveu-se a partir do século XVII tanto na forma disciplinar, quanto na biopolítica. Por um lado, como uma anatomopolítica do corpo humano, por meio do adestramento, da ampliação das aptidões, da extorsão das forças e do crescimento da utilidade e docilidade. Por outro lado, como uma biopolítica da população, por meio da regulação dos nascimentos, da mortalidade, do nível de saúde, da longevidade, da habitação, da migração e de uma série de intervenções e controles. Somadas, essas duas estratégias de normalização teriam sido responsáveis por uma radical reformulação no antigo poder de soberania, deslocando o eixo da velha potência da morte para a administração dos corpos e a gestão calculista da vida. Assim, Foucault (1988, p. 134-135) argumenta que a vida e seus mecanismos ingressaram no domínio dos cálculos explícitos, fazendo proliferar as tecnologias políticas que a partir de então passaram a investir sobre o corpo, a saúde, a sexualidade, as condições de vida e praticamente todo o nosso modo de ser.

Podemos pensar a cidade de modo similar ao sexo, como um domínio no qual também convergem mecanismos de poder disciplinares e biopolíticos. Na smart city, encontramos uma clara preocupação de governo da população, por meio de levantamentos estatísticos e de um refinado tratamento algoritmo de dados em grande escala e em tempo real, assim como uma atenção individualizada, uma tática disciplinar que enfatiza a docilização dos corpos e a apropriação 
máxima de cada indivíduo. Na cidade inteligente, tudo é otimizado, tornado útil, inclusive os sujeitos que nela vivem uma vida cada vez mais modelada, direcionada e controlada.

\section{A PERSONALIZAÇÃO DA EXPERIÊNCIA URBANA E A PERDA DO GOMUM}

Diante dessa utopia, contudo, muitas questões bastante inquietantes podem ser levantadas. Perspectivas críticas apontam para o fato de que esse sonho pode, talvez, converter-se em um grande pesadelo. A tecnologia muitas vezes oferece aquilo que acreditamos que queremos, ou que queremos acreditar que queremos. Mas o problema é que comumente não sabemos bem o que realmente queremos e muito menos o modo de atingir a felicidade e realizar nossos verdadeiros sonhos. Afinal, será que o que buscamos mesmo é mais eficiência? Tendemos a acreditar que sim, pois pensamos em termos imediatos, sem atentar para as consequências mais amplas em nossas vidas. Se, por um lado, é verdade que não gostamos de perder tempo, é preciso considerar que, por outro lado, a ideia de uma vida na qual não se perde nunca tempo algum é claramente um pesadelo. Queremos serviços rápidos e eficientes, em qualquer local que estejamos e em tempo real, mas a perspectiva de sermos monitorados o tempo inteiro e de termos nossa privacidade invadida sistematicamente não nos parece tão desejável assim. Queremos segurança e conforto, mas não fica claro muitas vezes o preço que deverá ser pago por tanta "comodidade". Em suma, somos frequentemente míopes com relação aos projetos de vida ou de cidade que construímos, discernindo apenas aquilo que está mais próximo de nossas vistas e deixando 
fora de foco e embaçado aquilo que se coloca mais distante, em um horizonte mais amplo.

Jogando com as palavras, podemos dizer que a "inteligência" dessa cidade sonhada talvez seja mais da ordem da esperteza, algo mais próximo da malandragem, da astúcia ou da capacidade de obter resultados vantajosos em curto prazo, mas sem necessariamente ser acompanhado de uma inteligência mais abrangente. A expressão inglesa smart city pode, aliás, ser perfeitamente traduzida por "cidade esperta". Em sentido pejorativo, pode até ser associada a uma espécie de "sabichão metido a besta" (smart-ass), um tipo de arrogante que crê ingenuamente tudo saber. É curioso perceber que a palavra smart serve ainda na língua inglesa para designar, em sentido figurativo, algo teleguiado, dirigido, como vemos em míssil teleguiado ou bomba inteligente (smart bomb). Assim, o habitante dessa nova utopia de cidade parece mais propriamente um espertalhão teleguiado, um consumidor que abriu mão de sua liberdade para viver confortavelmente. Em contraposição a isso, talvez pudéssemos imaginar uma “cidade sábia” (wise city), marcada não apenas pelo conhecimento, mas, sobretudo, pela capacidade de agir com sensatez e prudência. Não seria o sábio antigo, virtuoso, justamente aquele que se vale da razão para guiar a si mesmo e para construir uma vida feliz em comum, sendo capaz de ver melhor e mais longe? Em suma, o inverso dessa figura do espertalhão hi-tech dos dias de hoje.

As novas tecnologias da informação e seus usos para fins governamentais parecem ainda aumentar de maneira significativa a assimetria de poder entre, por um lado, aqueles que detêm as informações e a capacidade de operação algorítmica em grande escala, e, por outro lado, aqueles que apenas emitem dados e são governados. Em geral, não tomamos 
conhecimento do funcionamento desses sistemas computacionais autonômicos. E mesmo quando estamos cientes, somos, em regra, levados a crer que esse é o custo inevitável que devemos necessariamente pagar em troca dos novos serviços e das novas funcionalidades dos dispositivos digitais. Tendemos a olhar apenas para os efeitos imediatos, sem nos darmos conta das consequências de longo prazo que isso pode trazer para nossas vidas.

Nessas "cidades inteligentes", somos tratados basicamente como consumidores ou usuários. Raramente somos vistos como cidadãos, no sentido de sujeitos livres que podem tomar parte nas decisões coletivas. A governamentalidade algorítmica esvazia em grande medida o campo da política, elimina o debate público e procura solucionar os problemas, incluindo a organização urbana, em termos apenas de eficiência, inovação e segurança. Trata-se de uma espécie de nova tecnocracia digital que reaviva o sonho de resolver o problema da política por meio da ciência e da tecnologia, substituindo a deliberação pelo cálculo. No lugar do árduo e lento trabalho de construção democrática de uma vida em comum, entra em cena a solução rápida e eficiente das novas máquinas inteligentes.

Como ressalta Sadin (2015, p. 82-83), o ambiente inteligente condizente com esse novo sonho de cidade está assentado sob um fundo ideológico de natureza tecnocrática, que nutre um ódio pelas instituições democráticas da velha política e considera ineficiente, infrutífera e danosa a submissão das instâncias decisórias à vontade dos próprios cidadãos envolvidos. Em suma, o que move basicamente esse movimento são, em linhas gerais, interesses estritamente comerciais, que conduzem, sob uma modalidade inédita, em 
direção a uma gigantesca operação de privatização do espaço urbano. De acordo com Sadin (2015, p. 84, tradução minha):

Isso é a nova era da mercantilização da cidade contemporânea: um conhecimento incessantemente aprofundado e partilhado dos comportamentos pelo regime público e privado, que conjunta e tacitamente favorecem o encontro adequado entre o cidadão-consumidor e toda oferta considerada apropriada. Mudança de encantamento bastante imperceptível, mas que transforma completamente não exatamente a forma da cidade, mas sim as relações estabelecidas com todas as suas virtualidades, que passam a ser movidas pelo ajuste robotizado que visa prioritariamente o lucro, procedendo no caso a caso e em tempo real.

Em seus cursos ministrados entre 2012 e 2014 no Collège de France, publicados com o título A governança por meio dos números, o jurista francês Alain Supiot (2015, p. 11) defende que estamos diante de uma maneira inédita de representar o funcionamento do homem e da sociedade, uma experiência radicalmente nova que coloca em questão a figura do Estado tal como a conhecemos desde a modernidade. As noções de "Estado", "lei" e "democracia" sofrem transformações profundas, apontando para um novo modelo de governo dos homens. Partindo das reflexões de Foucault sobre a governamentalidade, Supiot (2015, p. 21) procura retraçar a história das diferentes promessas de um governo impessoal dos homens, passando pela referência a Deus, ao mercado e, recentemente, aos dados ou números. De formas distintas, somos sempre levados a submeter o direito e as instituições políticas a forças que escapam à deliberação humana. Assim como na experiência dos regimes totalitários, Supiot $(2015$, p. 22) vê o Estado assumir novamente um papel meramente instrumental, não mais o instrumento de um partido único que encarna o sentido da 
história, mas sim o instrumento de um “mercado total”, que engaja todos os indivíduos e regula os mais diversos aspectos da vida humana por meio de um cálculo econômico. $\mathrm{O}$ reino do direito é então superado. Em seu lugar, instala-se a governança por meio dos números, um capítulo a mais no sonho reavivado de uma harmonia social proporcionada pelo cálculo e pela técnica. No seio do imaginário redentor de uma "revolução digital", a normatividade da vida social deixa de ser pensada em termos de uma legislação, fruto de uma deliberação dos próprios cidadãos, para ser vista como uma programação, supostamente mais eficiente e inteligente, a serviço de imperativos próprios à expansão do capital.

A smart city caminha assim de mãos dadas com o sistema capitalista de produção. $\mathrm{O}$ governo algoritmo pode ser visto como o subsolo, o lado sombrio que torna possível o avanço do capital, que assume contemporaneamente a forma de um novo capitalismo da informação. Esse processo pode ser pensado de modo similar ao desenvolvimento do capitalismo industrial sobre o solo formatado pelos mecanismos disciplinares. Nesse sentido, Michel Foucault defende em Vigiar e punir que a generalização dos dispositivos disciplinares pode ser vista como a vertente obscura do processo das Luzes de instalação de um quadro jurídico burguês explícito. Em outras palavras, segundo Foucault (1999, p. 209):

A forma jurídica geral que garantia um sistema de direitos em princípio igualitários era sustentada por esses mecanismos miúdos, cotidianos e físicos, por todos esses sistemas de micropoder essencialmente inigualitários e assimétricos que constituem as disciplinas.

Foucault argumenta que o panoptismo constituiu o processo técnico de coerção difundido no meio social, fazendo 
funcionar mecanismos efetivos de poder, de tipo disciplinar, que eram incompatíveis com os quadros formais solenemente declarados no nível jurídico. Assim, as disciplinas são vistas por Foucault (1999, p. 210) como algo mais do que um "infradireito", no sentido de um mero prolongamento mais minucioso e pervasivo das leis, mas sim como um "contradireito", na medida em que funcionam ao arrepio das leis, produzindo assimetrias e efetuando uma suspensão das prerrogativas próprias aos sujeitos de direito.

No primeiro volume da História da Sexualidade: a Vontade de Saber, Foucault (1988, p. 132-133) prolonga essa reflexão, incluindo nela os mecanismos biopolíticos, considerados também indispensáveis ao desenvolvimento do capitalismo. Em suma, o capitalismo industrial seria impensável sem a inserção controlada dos corpos no aparelho de produção e sem um ajuste dos fenômenos de população aos processos econômicos. Assim, as técnicas de poder de anátomo e biopolítica agiram de maneira decisiva no nível das forças que estão em ação e sustentam os processos econômicos, garantindo a manutenção de relações de dominação.

No caso da nova governamentalidade algorítmica, podemos ver nela o mecanismo que sustenta o avanço dos processos próprios ao capitalismo da informação, também em claro contraste com diversos direitos assegurados, especialmente no campo da privacidade e no exercício da cidadania. As considerações feitas por Foucault sobre as sociedades capitalistas industriais oferecem assim um bom ponto de partida para se pensar a nova racionalidade governamental neoliberal, ou talvez sua nova versão algorítmica, que avança ainda mais sobre o campo econômico e também no nível da produção subjetiva, dando forma a novos sujeitos 
quantificados e exaustivamente apropriados no seio da nova vida digital nas cidades inteligentes.

Pensando mais diretamente a questão da cidade, encontramos no seio no movimento situacionista uma importante e radical reflexão sobre a experiência urbana. Henri Lefebvre, um filósofo marxista francês que participou da Internacional Situacionista no início dos anos 1960 e tratou da influência do sistema capitalista sobre o espaço urbano, observava que a definição de cidade como uma rede de circulação e de consumo não passa de uma ideologia urbanística particularmente arbitrária e perigosa, que se apresenta como uma verdade inquestionável. Isso, de acordo com Lefebvre (2001, p. 48-49), "leva ao urbanismo dos canos, da limpeza pública, dos medidores, que se pretende impor em nome da ciência e do rigor científico". Tal ideologia implicaria, em sua visão, em uma teoria da racionalidade e da organização, sendo indispensável uma crítica radical do urbanismo ideológico.

Essa crítica mais radical foi, em grande medida, levada adiante pelos situacionistas, em especial por Debord e Constant. Em A sociedade do espetáculo, Debord (2005, p. 119127) dedica uma seção inteira à ordenação do território, enquanto Constant levou a cabo um projeto inovador de cidade, a Nova Babilonia. Buscava-se, no seio de uma revolução do cotidiano, pensar os espaços urbanos como lugares de experimentação radical, de perpétua crítica, intervenção e estranhamento. Sonhava-se com um cotidiano jamais domesticado, que sempre propiciaria uma vida rica em experiências, distante da distração e da vivência indiferente e apática na metrópole. Propunha-se a deriva (détournement), o deixar-se levar pelas solicitações da própria paisagem, a esmo, vagabundeando de maneira errante, sem 
nenhuma rota pré-definida e em claro contraste com qualquer ideal de utilidade e eficiência. Segundo Velloso (2002, s.n.), "o habitante da cidade situacionista é aquele que aprende a explorar formas de vida radicalmente alheias ao capitalismo vigente, espécie de homo ludens que não se desintegra em homo faber, esse usuário contumaz do turismo administrado".

Se a internet e o mundo digital foram, em sua origem, vistos de forma libertária, como uma espécie de terra da liberdade e da pluralidade, somos hoje cada vez mais levados a pensar que talvez se trate do contrário. Em seu livro $O$ filtro invisível, Eli Pariser (2012) mostra como as informações são sistematicamente filtradas e chegam até nós de forma personalizada, sem que tenhamos quase nenhuma consciência ou controle sobre isso. Vivemos em uma espécie de "bolha digital", nas quais tendemos a ficar cada vez mais aprisionados. Ao invés de nos confrontarmos com os "outros", com a pluralidade, somos contrapostos a sempre "mais do mesmo", uma incessante repetição daquilo que já somos e que o algoritmo antecipa e direciona (PARISER, 2012, p. 14-20). Em suma, somos levados a viver em um mundo confortável, feito aparentemente "sob medida" para cada um de nós. A antiga imagem da navegação na internet, que remetia a uma espécie de aventura no oceano aberto da informação, deve talvez ser substituída por outra imagem, a de uma excursão guiada e controlada em um lago artificialmente produzido.

Isso talvez explique a dificuldade crescente nos dias atuais de lidarmos com os outros, com os diferentes de nós. As bolhas digitais parecem favorecer a perda da alteridade e a explosão dos discursos de ódio. Vivemos cada vez mais pre- 
sos a espaços personalizados, moldados de maneira individualizada, com publicidades direcionadas e relações cuidadosamente construídas, com "amigos" convenientes e conformados às nossas crenças e desejos. Desse modo, a experiência comum tende a enfraquecer-se ou mesmo se perder. Em nome do conforto e da eficiência, sacrifica-se a noção do "comum”, daquilo que é o mesmo para todos, daquele espaço da diversidade, no qual somos instados a conviver com as diferenças e a desenvolver a tolerância, a civilidade e a alteridade.

O sonho da smart city parece caminhar no sentido oposto à experiência comum da cidade, em direção a uma crescente personalização. Somos cada vez mais identificáveis, de modo que os ambientes podem ser devidamente preparados e moldados para "facilitar" ou tornar mais “confortável” nossa vida. Sadin (2015, p. 84-85) oferece um exemplo interessante nesse sentido: o sistema MyMagic+ implementado no parque da Disney em Orlando. Cada visitante recebe um bracelete com o rosto do Mickey que oferece informações e permite sua geolocalização. Desse modo, a organização do parque consegue modular o fluxo de pessoal e a oferta de atrações em função da taxa de densidade verificada ou projetada para certo local, além de acolher cada cliente em sua língua (quando possível) e pelo seu nome. Se a figura típica do turista já era a imagem mesma do consumidor que pouco interagia com as culturas locais, sem que se impusesse a ele praticamente nenhum esforço para lidar com o "outro", com o diferente de si mesmo, agora esse tipo de efeito parece intensificar-se, pois o turistaconsumidor-conectado circula em um espaço artificial e personalizado que insistentemente se molda confortavelmente 
ao seu mundo e evita praticamente todo tipo de confrontação com algo diferente, mesmo em termos linguísticos.

Parece muito cômodo, mas, como ressalta Éric Sadin, essa configuração geral do parque da Disney tende a impregnar a condição urbana em geral, dando forma a uma dinâmica social mediatizada por sistemas concebidos para evitar toda perda de tempo, para eliminar todo desconforto e para obter o máximo de lucro. Em suma, estamos diante da metáfora da "cidade biológica”, do grande organismo ordenado, do formigueiro humano eficiente que se impõe sobre toda instância decisória ou sobre a escolha livre dos indivíduos que nela vivem. Segundo Sadin (2015, p. 85, tradução minha):

A smart city corresponde ao sonho de reduzir a multiplicidade constitutiva da cidade a um órgão homogeneizado autorregulado, em um plano indiferenciado de cálculos tratados para responder em concerto e seguindo interesses definidos às aspirações 'naturais' de todos os seus membros.

Os situacionistas podem ser vistos, nesse ponto, como os mais radicais críticos desse sonho, apontando para uma direção diametralmente oposta. Eles chegaram a aprofundar suas ideias no campo urbanístico, desenhando uma nova arquitetura e esboçando novos projetos de cidade. A Nova Babilônia proposta por Constant pretende ser uma cidade nômade, permanentemente remodelada pela deriva de seus habitantes. Cai por terra a figura do arquiteto planejador, que impõe um modelo e um modo de vida a seus habitantes, supostamente mais confortável, seguro e eficiente. As mudanças espontâneas são privilegiadas e preza-se por uma determinada desorientação na cidade, por meio de formas labirínticas e mutáveis. Mais do que um projeto, a Nova Ba- 
bilônia é concebida por Constant como um empreendimento coletivo, no qual são apenas delineados os quadros gerais para a construção de situações por seus próprios habitantes. Trata-se de inspirar e não de prescrever um modo de vida (SADLER, 1998, p. 122-123). O habitante babilônico empenha-se na construção de suas situações e altera continuamente seu ambiente. Privilegia-se a liberdade e a criatividade na construção da vida em comum, em claro contraste com os imperativos utilitários. Trata-se de uma utopia que caminha na direção aposta ao sonho da cidade inteligente. Um exemplo ilustra bem esse ponto. Enquanto todos os serviços urbanos da smart city são planejados, incluindo uma iluminação pública inteligente, eficiente e de baixo custo, os situacionistas propõem instalar interruptores nos postes para que os próprios habitantes tenham controle sobre a luz.

Mais contemporaneamente, encontramos no filósofo e urbanista francês Paul Virilio, falecido recentemente, uma perspectiva crítica em relação à "cidade virtual". Em seu livro A bomba informática, Virilio reflete sobre a perda da noção de realidade na era da informática, assumindo uma posição crítica ao neoliberalismo, à globalização do capital e ao novo império da técnica, do ciberespaço à automação. Dedicando uma atenção especial à questão urbana, Virilio (1999, p. 18) sustenta que a "cidade real" estaria cedendo seu lugar para a "cidade virtual", que não passaria de uma "metacidade desterritorializada" de caráter totalitário. Virilio (1999, p. 69) denuncia uma política que se tornou ao mesmo tempo panóptica e cibernética, vigiando, enquadrando e direcionando o agir humano. Nasceria assim, segundo Virilio (1999, p. 107), uma "democracia 
automática" ou "democracia-reflexa”, na qual o automatismo social e o condicionamento ocupam o lugar da deliberação e eliminam qualquer espaço de reflexão coletiva. Da autoridade dos homens sobre sua história, somos levados, na ótica de Virilio (1999, p. 118-119), à “autoridade das máquinas", uma “cibernética social” capaz de administrar nossas vidas e realizar o cúmulo do processo técnico: o sonho de uma tecnocracia por meio de um sistema autômato de organização social.

\section{O GRANDE PERIGO PARA A LIBERDADE}

Algumas inquietações surgem quanto ao perigo que esse "sonho" da cidade inteligente, governada por algoritmos, apresenta para a nossa liberdade. Quanto mais informações nós disponibilizamos, mais nos tornamos transparentes para os algoritmos que "facilitam" a nossa vida, mais nos tornamos conhecidos em nossos mínimos detalhes, e cada vez mais os algoritmos serão capazes de antecipar nossas condutas, oferecer serviços e direcionar nossas ações. Mas é um equívoco acreditar que os algoritmos simplesmente oferecem aquilo que queremos. Mais do que isso, eles fazem com que algo seja desejável (ROUVROY; BERNS, 2015, p. 44). Interessante recordar nesse ponto a análise desenvolvida ainda nos anos 1940 e 1950 pelos frankfurtianos sobre a indústria cultural, que, mais do que atender ao desejo do público, produz o desejo de consumo. Não se trata de simplesmente dar às pessoas o que elas querem, mas sim de fazer com que se queira isso ou aquilo. No mundo administrado, o sujeito é objetificado e não livre. Em suma, é preciso que o sujeito acredite que quer realmente aquilo que se quer 
que ele queira. E com os novos recursos, o sujeito parece tornar-se ainda mais débil, incapaz de raciocinar e deliberar por conta própria, sendo facilmente levado (sem que ele se dê conta disso) na direção que se deseja.

Com o tempo, podemos imaginar um mundo no qual seremos praticamente conduzidos por esses algoritmos. Qual caminho é melhor seguir? Qual meio de transporte utilizar? Qual filme assistir? Para qual restaurante vou hoje? Qual livro é melhor comprar? Para qual supermercado vou e o que devo comprar? O que farei neste final de semana? Qual roupa ou corte de cabelo fica melhor em mim? Com quem devo namorar? Em suma, os algoritmos sabem melhor do que nós mesmos as respostas, basta se deixar governar por eles para não perder tempo e para chegar mais fácil naquilo que "você quer". Em outras palavras, são os algoritmos que farão as escolhas e são eles que dirão o que eu quero.

Em uma entrevista publicada no The Wall Street Journal em 2010, Eric Schmidt, um dos diretores da Google, deixa essa pretensão explícita: "Eu realmente penso que a maioria das pessoas não quer que a Google responda suas perguntas. Elas querem que a Google lhes diga o que deveriam fazer em seguida" (JENKINS JR., 2010, s.n., tradução minha). Em outra entrevista publicada no Financial Times em 2007, Eric Schmidt deixa clara sua empolgação com as possibilidades abertas pelas informações que alimentam o algoritmo da Google e suas ferramentas de personalização, explicitando também dessa vez seu desejo de direcionar a ação futura: “O objetivo é permitir que os usuários da Google possam perguntar algo como 'o que devo fazer amanhã?' e 'qual emprego devo ter?'” (DANIEL; PALMER, 2007, s.n., tradução minha).

Em um mundo governado através de algoritmos, parece 
sobrar pouco espaço para ações espontâneas. Talvez Eric Schmidt tenha razão ao afirmar que, quando a tecnologia for mais avançada e eficiente, "será muito difícil uma pessoa assistir ou consumir algo sem que tenha sido de alguma forma dirigida para isso" (JENKINS JR., 2010, s.n., tradução minha). Diante desse quadro, o campo da liberdade e da deliberação corre o risco de ser colonizado por processos racionalizados e autômatos capazes de nos governar. Estamos cada vez mais longes da concepção aristotélica de cidade como uma comunidade de animais políticos.

Temendo o desenvolvimento desse processo, Rouvroy (2011, p. 134) chega a associar a espontaneidade, ou a virtualidade que torna a ação imprevisível, algo essencial ao humano, fundamental para o processo de subjetivação e também para as utopias sociais, na medida em que permite que possamos nos transformar a nós mesmos em termos éticos ou políticos, ou seja, enquanto indivíduo e também como coletividade. A pretensão de objetividade da governamentalidade algorítmica conduz, no limite, ao esquecimento da escolha política. É possível conduzir a ação sem se preocupar com o seu sentido. Trata-se de uma espécie de "política da simulação", na qual as ações passam a ser governadas graças ao feedback dos parâmetros que indicam os cenários futuros produzidos com base nas predisposições estatísticas de cada perfil. Em suma: não se age, não se cria, modula-se. E neste cenário de behaviorismo ou comportamentalismo digital, as próprias bases da política, quais sejam, a deliberação e o espaço público, são gravemente atingidas. Assim como as possibilidades de resistência e emancipação. O problema está no fato de o governo algorítmico não dar lugar a um sujeito ativo, capaz de legitimar ou resistir a esse governo 
(ROUVROY; BERNS, 2015, p. 47). Talvez estejamos sacrificando nossa liberdade, no sentido de uma ação autônoma, espontânea, deliberada, refletida, capaz de transgredir ao que é dado e resistir ao que é imposto, trilhando assim novos e imprevisíveis caminhos.

É de se perguntar se a cidade governada por algoritmos deixa algum espaço para autênticas experiências, no sentido de algo do qual saímos nós mesmos transformados. Fica eliminado aquele encontro insuspeito, aquela palavra perturbadora, aquela cena incômoda, aquele ato transgressor. No lugar disso, impera a vida programada, segura, confortável e "feliz". Parodiando Platão, diríamos que também os filósofos deveriam ser expulsos dessa cidade ideal. Afinal, sempre coube a eles a crítica ao senso comum, o ato corajoso da voz dissonante, a atitude inquietante e a ousadia da transformação de si mesmos e do mundo em que vivemos.

Sem dúvida, todo aquele que parece colocar em risco nossa segurança e conforto tende a ser malvisto, proscrito, rejeitado como um elemento inconveniente. Talvez Nietzsche, em Sobre verdade e mentira em sentido extramoral, tenha razão ao afirmar que o homem não ama a verdade por si mesma. O que ele ama, acima de tudo, é a possibilidade de conservação, o que há de agradável. Por isso, preferimos viver sem questionar velhas mentiras confortáveis, pois é duro aceitar uma verdade incômoda. Desejamos a verdade apenas quando é agradável e conserva a vida que desejamos, fora disso, optamos facilmente por viver iludidos. Assim, preferimos eliminar quem ameaça nossa tranquilidade. $\mathrm{O}$ homem basicamente "quer existir socialmente e em rebanho", em paz e segurança, por isso, como diz Nietzsche (1983, p. 46-47), o que se odeia não é tanto o engano ou a ilusão, o grande medo é o de ser prejudicado de alguma 
forma.

Deixar-se governar por algoritmos pode até ser eficiente e confortável quando olhamos apenas para os resultados mais imediatos, mas pode também conduzir, no limite, a um processo de desumanização, a uma objetificação do humano por meio das máquinas e dos dispositivos que ele mesmo colocou em operação.

\section{CONSIDERAÇÕES FINAIS:}

Até o século XX, viver em uma cidade parecia necessariamente implicar o compartilhamento de um espaço comum e a relação imperativa com o "outro". Talvez as recentes tecnologias da informação e da comunicação estejam apontando para outro tipo de experiência urbana, que realiza alguns sonhos associados ao conforto, à segurança e à eficiência, mas traz consigo uma série de novos desafios e problemas até então insuspeitos. Ao invés de incentivar o compartilhamento do comum, a livre circulação e a sensibilidade à alteridade, a smart city privilegia o espaço personalizado, o comportamento dirigido e a repetição do mesmo. Podemos até viver confortavelmente neste mundo moldado sob medida para cada um de nós, mas pagamos caro por essas facilidades.

Ao longo do presente artigo, procurou-se pensar essa questão a partir da noção de "governamentalidade algorítmica”, entendida aqui nas linhas propostas por Antoinette Rouvroy como um tipo de racionalidade governamental baseado na coleta em grande escala, na mineração dos dados e na elaboração de perfis com visada preditiva, conformando ambientes e direcionando a ação humana. Na primeira parte do texto, foi ressaltada a base foucaultiana dessa noção 
de "governamentalidade" e, na sequência, o trabalho caminhou para pensar a contemporaneidade e especialmente a utopia da smart city. Após apresentar em suas linhas gerais esse sonho de uma cidade governada por algoritmos, algumas reflexões críticas foram desenvolvidas, tomando por base diferentes pensadores atuais, como Éric Sadin, Alain Supiot, Paul Virilio e os situacionistas Henri Lefebvre, Guy Debord e Constant Nieuwenhuys. As principais considerações críticas analisadas estão relacionadas à perda da experiência comum, à relação do projeto da smart city com o avanço do capitalismo da informação, e ao possível comprometimento que esse tipo de automatismo poderia trazer à espontaneidade e à liberdade. $\mathrm{O}$ foco principal da crítica caminhou na direção de uma denúncia do caráter antidemocrático dessa ilusão de uma nova tecnocracia digital, pretensamente capaz de solucionar os problemas tradicionalmente políticos por meio de cálculos realizados por máquinas inteligentes.

Apesar de o tom das reflexões desenvolvidas aqui ser majoritariamente tecnófobo, é importante deixar claro que o objetivo não foi criticar em bloco toda a tecnologia e assumir uma posição saudosista e passadista. Se a concepção meramente instrumental da tecnologia deve ser rejeitada, pois os meios não são simplesmente neutros, também não me parece adequado sustentar uma concepção determinística da tecnologia, como se seus artefatos conduzissem a humanidade necessariamente em certa direção. Entende-se que há uma abertura, uma possibilidade de múltiplas apropriações e de usos os mais variados. Os próprios artefatos podem ser redesenhados e os algoritmos reprogramados, de modo a exercerem novas funções e produzirem outros efeitos sociais e políticos. É possível uma racionalização subversiva ou uma 
revolução digital não necessariamente associada aos imperativos neoliberais e à expansão do capital. Nesse sentido, convém recordar que o projeto radical da cidade situacionista da Nova Babilônia é, de acordo com Constant, produto de uma tecnocracia criativa e não utilitarista (SADLER, 1998, p. 151). A proposta de Constant não era, portanto, ignorar ou reprovar a tecnologia, mas sim fazer um uso emancipatório de suas potencialidades, fazendo-a funcionar a serviço da agenda situacionista.

Concluindo, talvez estejamos sendo míopes ao ver na smart city a realização do sonho de uma vida confortável e feliz. Isso porque a vida dirigida e programada de maneira maquínica pode cobrar seu preço. E um preço bem alto: o comprometimento do sujeito autônomo, capaz de agir de forma deliberada, espontânea e imprevisível. Até onde devemos levar nosso desejo por segurança, eficiência, previsibilidade e conforto? Não estaríamos, talvez, bloqueando o risco inerente à liberdade humana? Até que ponto é possível conjugar vida livre e vida segura? Até que ponto é compatível o conforto com a ousadia do pensamento e a permanente inquietude que nos leva a buscar uma incessante transformação de nós mesmos e do mundo em que vivemos? Como ensinava Guimarães Rosa (1994, p. 778), viver é muito perigoso: "Travessia perigosa, mas é a da vida".

Abstract: Based on Michel Foucault's reflections in the late 1970s and the more recently developed notion of "algorithmic governmentality", understood as a new regime of power and knowledge based on the collection, mining and crossing of large amount of data, this article intends to analyze critically the so-called "smart cities", in which infrastructure and services are linked in a supposedly more streamlined and efficient way, finally offering the dreamed well-being and happy life. This utopia of social organization will be associated with a new form of political rationality and strategy of government by means of algorithms, which raise important and disturbing questions. In this work, we will highlight the ability of algorithms to govern us, in order to 
conduct our behaviors and structure the field of possible actions. And the focus of this article will be on the tension between freedom and control inscribed in this new governmentality, which acts more directly on data, relations and environments.

Keywords: Smart City. Algorithmic governmentality. Foucault. Freedom.

\section{REFERÊNGIAS}

ABITEBOUL, Serge; DOWEK, Gilles. Le temps des algorithmes. Paris: Éditions Le Pommier, 2017.

BARRY, Andrew; OSBORNE, Thomas; ROSE, Nikolas (eds.). Foucault and political reason: liberalism, neo-liberalism and rationalities of government. Chicago: The University of Chicago Press, 1996.

BRÖCKLING, Ulrich; KRASMANN, Susanne; LEMKE, Thomas (eds.). Governmentality: current issues and future challenges. New York: Routledge, 2011.

BRUNO, Fernanda. Máquinas de ver, modos de ser: vigilância, tecnologia e subjetividade. Porto Alegre: Sulina, 2013.

BRUNO, Fernanda. Rastrear, classificar, performar. Ciência e Cultura, vol. 68, n. 1, p. 34-38, 2016.

BURCHELL, Graham; GORDON, Colin; MILLER, Peter (eds.). The Foucault effect: studies in governmentality. Chicago: The University of Chicago Press, 1991.

CARDON, Dominique. À quoi rêvent les algorithms: nos vies à 1'heure des big data. Paris: Éditions du Seuil / La République des Idées, 2015.

CHRISTIAN, Brian; GRIFFITHS, Tom. Algorithms to live 
by: the computer science of human decisions. London: William Collins, 2016.

DANIEL, Caroline; PALMER, Maija. Google's goal: to organise your daily life. Financial Times, Londres, 22 mai. 2007. Disponível em: <https://www.ft.com/content/c3e49548-088e-11dc-b11e-000b5df10621>. Acesso em: 17 fev. 2018.

DEBORD, Guy. A sociedade do espetáculo. Tradução de Francisco Alves e Afonso Monteiro. Lisboa: Edições Antipáticas, 2005.

DESROSIÈRES, Alain. La politique des grands nombres: histoire de la raison statistique. Paris: Éditions La Découverte, 1993.

FOUCAULT, Michel. História da sexualidade I: A vontade de saber. Tradução de Maria Thereza da Costa Albuquerque e J. A. Guilhon Albuquerque. 13a ed. Rio de Janeiro: Graal, 1988.

FOUCAULT, Michel. O sujeito e o poder. In: DREYFUS, Hubert; RABINOW, Paul. Michel Foucault, uma trajetória filosófica: para além do estruturalismo e da hermenêutica. Tradução de Vera Porto Carrero. Rio de Janeiro: Forense Universitária, 1995, p. 231-249.

FOUCAULT, Michel. Vigiar e punir: nascimento da prisão. $20^{a}$ ed. Tradução de Raquel Ramalhete. Petrópolis: Vozes, 1999.

FOUCAULT, Michel. Segurança, território, população: curso dado no Collège de France (1977-1978). Tradução de Eduardo Brandão. São Paulo: Martins Fontes, 2008. 
GUIMARÃES ROSA, João. Grande Sertão: Veredas. São Paulo: Nova Aguilar, 1994.

HUNT, Alan. Governing the city: liberalism and early modern modes of governance. In: BARRY, Andrew; OSBORNE, Thomas; ROSE, Nikolas (eds.). Foucault and political reason: liberalism, neo-liberalism and rationalities of government. The University of Chicago Press, 1996, p. 167-188.

JENKINS JR., Holman W. Google and the search for the future. The Wall Street Journal, New York, 14 ago. 2010. Disponível em: <https://www.wsj.com/articles/SB10001424052748704901104575423294099527212 >. Acesso em: 17 fev. 2018.

LEFEBVRE, Henri. $O$ direito à cidade. Tradução de Rubens Eduardo Frias. São Paulo: Centauro, 2001.

LEMKE, Thomas. Foucault, governmentality, and critique. New York: Routledge, 2012.

MILLER, Peter; ROSE, Nikolas. Governando o presente: gerenciamento da vida econômica, social e pessoal. Tradução de Paulo Ferreira Valério. São Paulo: Paulus, 2012.

NIETZSCHE, Friedrich. Sobre verdade e mentira no sentido extra-moral. Tradução de Rubens Rodrigues Torres Filho. In: . Nietzsche. Coleção "Os Pensadores". São Paulo: Abril, 1983.

O'NEIL, Cathy. Weapons of math destruction: how big data increases inequality and threatens democracy. New York: Crown, 2016. 
PARISER, Eli. O filtro invisível: o que a internet está escondendo de você. Tradução de Diego Alfaro. Rio de Janeiro: Zahar, 2012.

PARRA, Henrique. Abertura e controle na governamentalidade algorítmica. Ciência e Cultura, vol. 68, n. 1, p. 3949, 2016.

ROUVROY, Antoinette. Technology virtuality and utopia: governmentality in an age of autonomic computing. In: ROUVROY, Antoinette; HIDELBRAND, Mireille (eds.). Law, Human Agency and Autonomic Computing: the philosophy of law meets the philosophy of technology. New York: Routledge, 2011, p. 119-140.

ROUVROY, Antoinette; BERNS, Thomas. Governamentalidade algorítmica e perspectivas de emancipação: o díspar como condição de individuação pela relação? Revista Eco Pós, vol. 18, n. 2, p. 35-56, 2015.

ROUVROY, Antoinette; STIEGLER, Bernard. Le régime de vérité numérique: de la gouvernementalité algorithmique à un nouvel État de droit. Socio: La nouvelle revue des sciences sociales, n. 4, p. 113-140, 2015.

SADIN, Éric. La vie algorithmique: critique de la raison numérique. Paris: Éditions L'Échappée, 2015.

SADLER, Simon. The situationist city. Cambride, Mass.: The MIT Press, 1998.

SUPIOT, Alain. La gouvernance par les nombres: cours au Collège de France (2012-2014). Paris: Librairie Arthème Fayard, 2015. 
TELES, Edson. A governamentalidade algorítmica e as tecnologias de controle dos corpos. In: LIMA, Nádia Laguárdia; STENGEL, Márcia; DIAS, Vanina Costa (orgs.). Anais do I Simpósio Internacional Subjetividade e Cultura Digital: corpo e virtualidade. Belo Horizonte: UFMG; PUC Minas, 2017, p. 318-324.

TELES, Edson. Governamentalidade algorítmica e as subjetivações rarefeitas. Kriterion, n. 140, p. 429-448, 2018.

TERRANOVA, Tiziana. Network culture: politics for the information age. London: Pluto Press, 2004.

VELLOSO, Rita de Cássia Lucena. Cotidiano selvagem: Arquitetura na Internationale Situationniste. Arquitextos, n. 027.02, ano 03, 2002. Disponível em: <http://www.vitruvius.com.br/revistas/read/arquitextos/03.027/758>. Acesso em: 2 dez. 2018.

VIRILIO, Paul. A bomba informática. Tradução de Luciano Vieira Machado. São Paulo: Estação Liberdade, 1999. 